\title{
Energy Recovery from Food Packaging Plastics by Thermal and Catalytic Pyrolysis Processes
}

\author{
Mochamad Syamsiro ${ }^{1,2, *}, Z^{2}$ ahrul Mufrodi ${ }^{3}$, Ricki Rafly ${ }^{1}$, Syahril Machmud ${ }^{1}$ \\ ${ }^{1}$ Department of Mechanical Engineering, Janabadra University, Indonesia \\ ${ }^{2}$ Center for Waste Management and Bioenergy, Janabadra University, Indonesia \\ ${ }^{3}$ Department of Chemical Engineering, Ahmad Dahlan University, Indonesia
}

Received November 9, 2019; Revised December 16, 2019; Accepted December 25, 2019

Copyright $\bigcirc 2020$ by authors, all rights reserved. Authors agree that this article remains permanently open access under the terms of the Creative Commons Attribution License 4.0 International License

\begin{abstract}
This study aims to investigate the thermal and catalytic pyrolysis of crushed instant noodle packs (CINP) and crushed coffee sachets (CCS) with and without calcined- natural zeolite catalysts. The experimental works were conducted using a small scale vertical tubular reactor heated by an electrical heater. The thermal pyrolysis experiments were carried out at the reactor temperature of 400,450 , and $500^{\circ} \mathrm{C}$. In the second experiments, catalyst was loaded on the upper side of the reactor at various catalyst to plastic ratio. The results show that CINP produced higher liquid product at lower temperature while CCS produced higher liquid product at higher temperature. The maximum liquid oil yield obtained up to $65 \%$ on CCS pyrolysis at the temperature of $500^{\circ} \mathrm{C}$. The presence of catalyst reduced the liquid fraction for both feedstocks and modified the chemical composition of the pyrolytic oil. The heating value of the pyrolytic oil was high enough for fueling the engine and other external combustion engines. CCS pyrolysis also produced much more solid product compared to CINP.
\end{abstract}

Keywords Instant Noodle Packs, Coffee Sachets, Pyrolysis, Fuel Oil, Natural Zeolite, Char Residue

\section{Introduction}

Municipal solid waste (MSW) has become a serious problem in several big cities in Indonesia, especially household waste, since the waste is very polluting our environment. There are still lots of waste without good handling in many places and even some waste was disposed into the river making it a problem with the whole community. One of the solid waste becoming major stream in our MSW is plastic waste.

The use of plastic materials increases in daily life in line with the improvement of the economic growth and social quality of life. This is due to the superiority of plastics compared to other types of materials including lightweight, strong, moldable, less expensive and corrosion resistant. These advantages resulted in more waste plastics being produced from households.

As a developing country, Indonesia continues to spur economic growth. The trend of economic growth increased from 2001, which was $4.90 \%$, reaching a peak in 2011 of 6.98\%, and it slowed in 2017 to 5.07\%. In 2016 the number of waste generation in Indonesia with the population of 261 million people was 65.2 million tons per year. The projection of the population of Indonesia shows that the population continues to grow and will certainly increase the amount of waste generation [1].

According to United Nations Environment summary report [2], the MSW generated in Indonesia is composed mainly of organic waste (60\%), followed by plastic (14\%) and paper (9\%) as shown in Figure 1. The main issue when disposing MSW is how to treat plastic waste because of their slow degradation rates. Plastic Waste should not be directly discarded via open dumping or landfilling system. Feedstock or chemical recycling by pyrolysis process is one of the proper solution to convert waste plastics into fuel which can be used for engine and other apllications.

Some previous studies have been conducted by many researchers using various feedstocks such as CD case [3], bottle caps, detergent bottles [4], polyethylene (PE) bag [5], and household plastic waste [6]. Several commercial and modified catalysts [7] have also been used to upgrade the quality of pyrolytic oil such as Ni-Ce [8], kaolin clay [9], Y zeolite [5] and ZSM-5 zeolite [10]. Natural zeolite catalyst has also been chosen as a cheaper catalyst to reduce the production cost of pyrolytic oil [11]. Utilization of pyrolytic oil in diesel engine has also been investigated by Syamsiro et al. [12], Venkatesan et al. [13], Ayodhya et al. [14], Chintala et al. [15], and other researchers [16]. 
Most of the waste plastic pyrolysis studies used recycled plastics which can also be recycled by using material recycling method to produce a lower grade plastic material. There are still few researches on non-recycled plastic pyrolysis which is very important to be implemented in developing countries like Indonesia. Therefore, the present works studied the pyrolysis of instant noodle packs and coffee sachets to produce liquid fuel by thermal and catalytic process using natural zeolite catalyst.

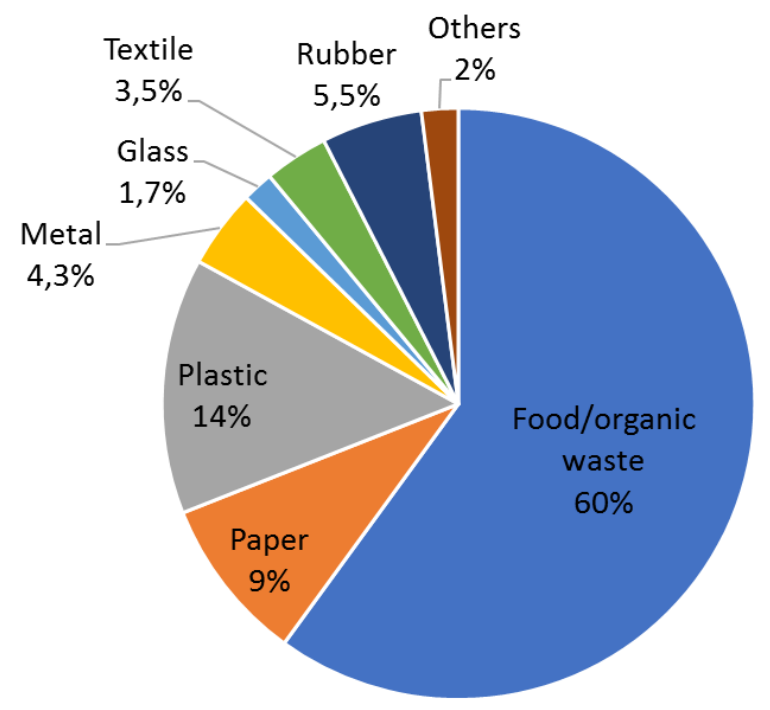

Figure 1. MSW composition in Indonesia [2]

\section{Materials and Methods}

\subsection{Materials}

The waste plastics used for these experimental works were instant noodle packs and coffee sachets after crushing and washing. The feedstocks were obtained from the local waste bank in Yogyakarta city, Indonesia. The appearance of the feedstock is shown in Figure 2. The materials were then crushed into smaller size to maximize the capacity of the reactor.

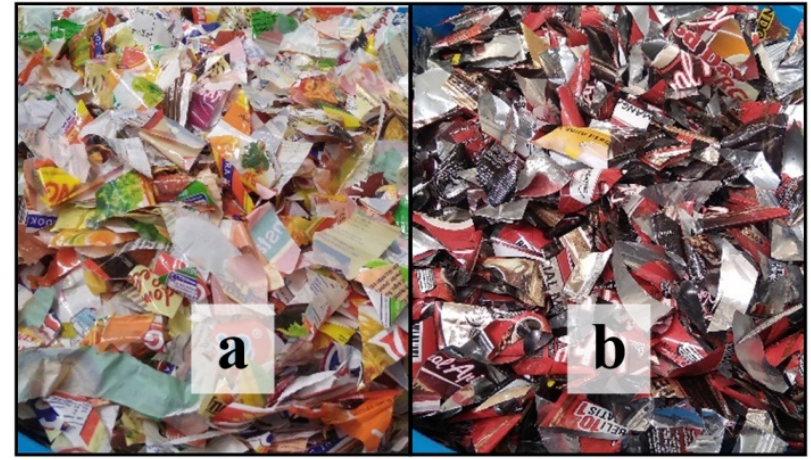

Figure 2. (a) Crushed instant noodle packs (CINP) and (b) crushed coffee sachets (CCS) as feedstock

The catalyst used for this works was natural zeolite. This natural catalyst was collected from Klaten, Indonesia. The fresh natural zeolite was dried in an oven at $120^{\circ} \mathrm{C}$ for 5 hours and then calcined at $500^{\circ} \mathrm{C}$ for 3 hours to remove some volatile substances. The characteristics of calcined natural zeolite (CNZ) catalyst has been reported in previous studies [5][11]. The CNZ sample can be classified as mordenite type cristalline based on XRD patterns. However, the catalyst sample contained some amorphous and crystalline impurities. The BET surface area of CNZ catalyst was $91.146 \mathrm{~m}^{2} / \mathrm{g}$. The snapshot of the calcined natural zeolite is shown in Figure 3.

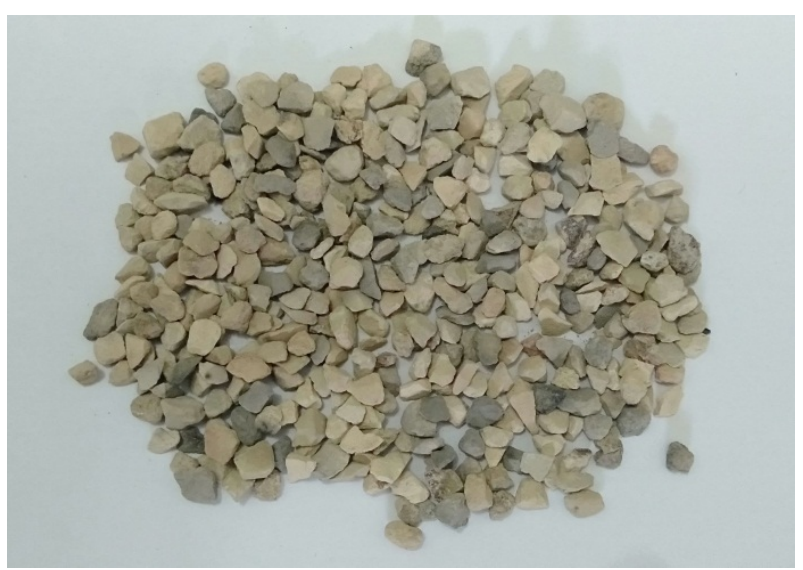

Figure 3. Calcined natural zeolite used in this study. 


\subsection{Pyrolysis Experimental Procedure}

The pyrolysis experimental works were conducted using a small scale vertical tubular reactor fabricated from stainless steel. An electrical heater was used to heat up the reactor. The height and the inner diameter of the pyrolysis reactor are $450 \mathrm{~mm}$ and $100 \mathrm{~mm}$, respectively. The reaction temperatures in the reactor were measured with K-type thermocouple and contolled by the heater. The condenser was connected to the outlet of reactor to condense the pyrolysis gas coming out from the reactor. The first condenser was cooled by the surrounding air and the second condenser is a double-pipe condenser which was cooled by the circulating water. A 3D schematic diagram of the apparatus is shown in Figure 4. The liquid product was then collected at the bottom of the condenser in the oil tank. The solid residue remained in the pyrolyzer and catalyst was then collected and weighed for calculating the mass balance.

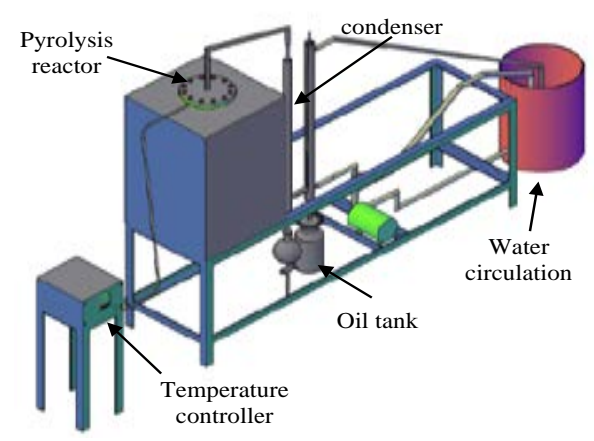

Figure 4. A 3D schematic diagram of the experimental apparatus

In each experiment, about $200 \mathrm{~g}$ of CINP or CCS was loaded into the pyrolysis reactor. The reactor was then closed and heated from room temperature to the targeted temperature. The feedstock was then melted and volatilized into gaseous phase and come out to the condenser for cooling and condensing the pyrolysis gas became pyrolytic oil. The thermal pyrolysis experiments were carried out at the reactor temperature of 400,450 , and $500^{\circ} \mathrm{C}$. In the second experiment, catalyst was loaded on the upper side of the reactor at various catalyst to feedstock ratio. The heating value of liquid and solid products was then measured by using bomb calorimeter. The fraction of liquid product was also analysed by using GC-MS (QP2010S Shimadzu).

\section{Results and Discussion}

\subsection{Pyrolysis of Instant Noodle Packs}

The product yield of the thermal pyrolysis of CINP as the effect of pyrolysis temperature is shown in Figure 5. The picture shows that the highest liquid yield was produced at the temperature of $400^{\circ} \mathrm{C}$. At this temperature, CINP produced a liquid yield of $64.5 \%$. It means that the CINP did not need high temperature for pyrolysis process.
As we know that CINP was composed of polypropylene (PP) which needs lower pyrolysis temperature compared to other materials such as polyethylene (PE).

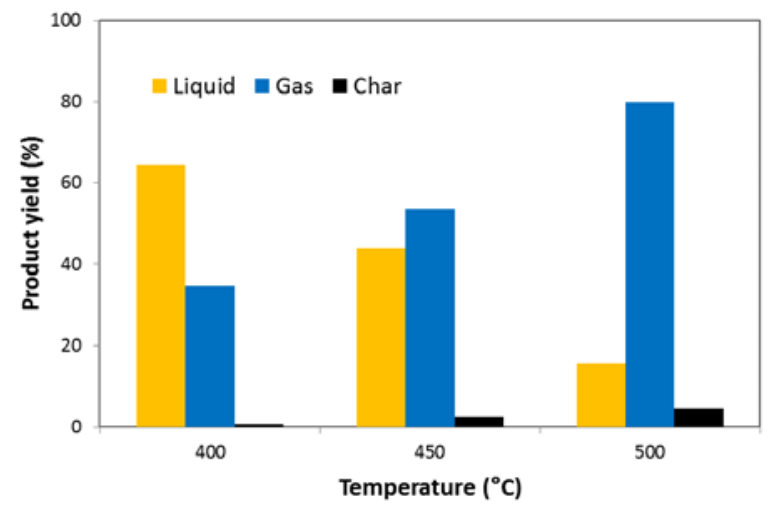

Figure 5. Effect of temperature on product distribution from the thermal pyrolysis of crushed instant noodle packs

Figure 5 also shows that the liquid yield would decrease along with the increase of temperature. On the contrary, the gaseous yield has increased with the increase of temperature. This is due to more intensively cracking reaction has occured at higher temperature. At this condition, longer chain hydrocarbon has been cracked into shorter chain hydrocarbon, so that some oil product was converted into gaseous product [3].

The study on the effect of catalyst presence can be seen in Figure 6. The result shows that the catalytic pyrolysis reduced the oil yield almost a half of the thermal pyrolysis. The maximum yield could be produced at the catalyst to plastic ratio of 0.5 which could obtain the liquid yield of $36.7 \%$. The presence of catalyst promoted an additional cracking reaction inside the catalyst so that some oil yield would also be transformed into gaseous yield.

The addition of catalyst in pyrolysis reactor was also intended to improve the quality of the oil product by changing the chemical composition of the oil. Figure 6 also shows some coked formation which can be seen from the increasing of the solid fraction. The coked formation would obstruct the heat transfer in the reactor and also reduce the active site numbers which leads to an increase in operating cost [17].

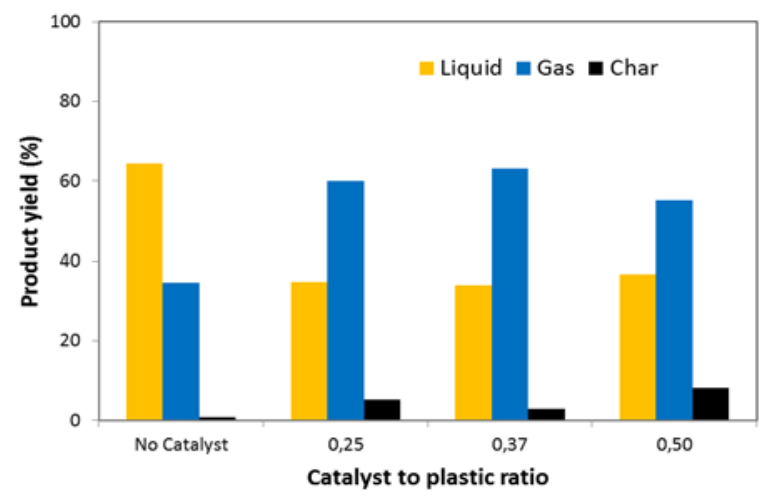

Figure 6. Effect of catalyst presence on product distribution from the pyrolysis of crushed instant noodle packs at the temperature of $400^{\circ} \mathrm{C}$ 


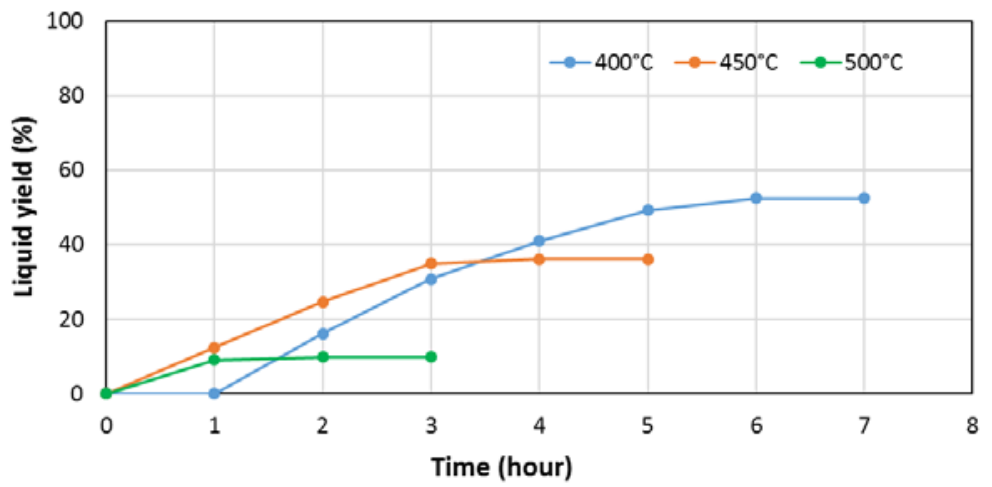

Figure 7. Liquid oil production rate at various temperature collected from condenser 1 for CINP feedstock

Figure 7 shows the liquid oil production rate produced from the thermal pyrolysis of CINP at various temperatures obtained from the first condenser. The liquid yield was mainly produced from the first condenser. The second condenser had only obtained the oil less than $15 \%$. From Figure 7 we can see that the fastest pyrolysis process could be achieved within 3 hours at the temperature of $500^{\circ} \mathrm{C}$, while the longest time was 7 hours at the temperature of $400^{\circ} \mathrm{C}$. The pyrolysis time is also the important parameter in this technology in commercial scale. The longer pyrolysis time means the higher operation cost since more fuel is needed to heat up the reactor.

\subsection{Pyrolysis of Crushed Coffee Sachets}

The effect of the reactor temperature on the product yields from the pyrolysis of cushed coffee sachets (CCS) is shown in Figure 8. It shows that the increase of the reactor temperature increased the yield of liquid product, whereas it decreased the yield of gaseous and solid products. The result shows the opposite trend compared to CINP feedstock as shown in Figure 5. The main component in CINP is polyethylene (PE) which has different characteristics compared to PP in CINP feedstock.

Typically PE has higher cracking temperature compared to PP due to the different structures of molecule from each material. Thermal pyrolysis of waste plastic is an endothermic process, therefore, the dissociation energy of the C-C bond must be provided to break down the plastic bond. The dissociation energy of PE is higher then that of PP so that it requires higher temperature for breaking down into smaller carbon chain [18]. Moreover, the quantity and quality of the product yield in thermal pyrolysis are affected by several parameters, such as type of reactor, temperature and residence time [19][20].

Figure 8 also shows that CCS produced much more solid product compared to CINP. The maximum solid product yield was $29.5 \%$ at the temperature of $400^{\circ} \mathrm{C}$. The reason is that CCS was laminated by aluminium foil which could not be pyroyzed into pyrolysis gas. The aluminium foil has remained in the reactor mixes with the solid residue.

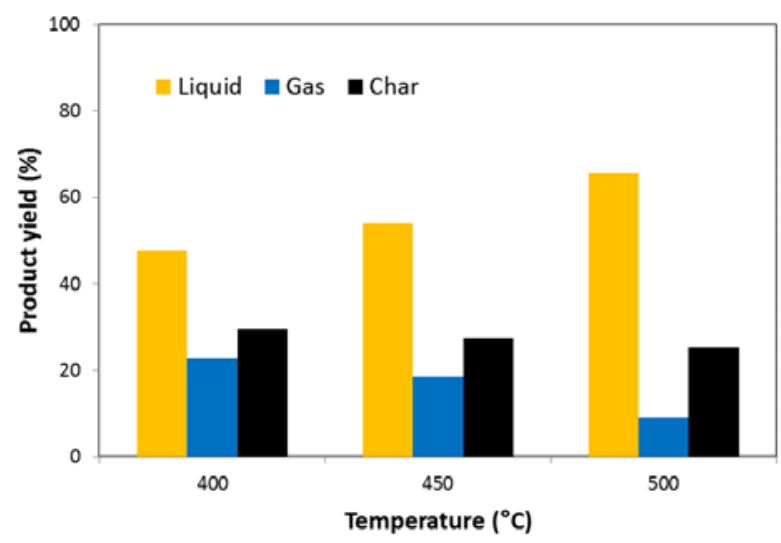

Figure 8. Effect of temperature on product distribution from the pyrolysis of crushed coffee sachets

Figure 9 shows the product yields generated from the catalytic pyrolysis of CCS as the effect of catalyst to plastic ratio. It can be seen that the presence of CNZ reduced the liquid fraction and increased the gaseous fraction. Theoretically, CNZ catalyst can intensify the cracking reaction of the pyrolytic gas.

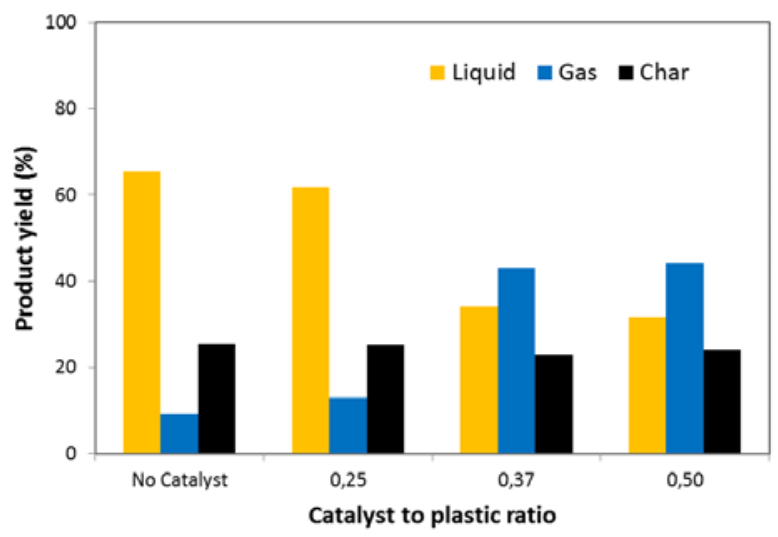

Figure 9. Effect of catalyst presence on product distribution from the pyrolysis of crushed coffee sachets at the temperature of $500^{\circ} \mathrm{C}$ 


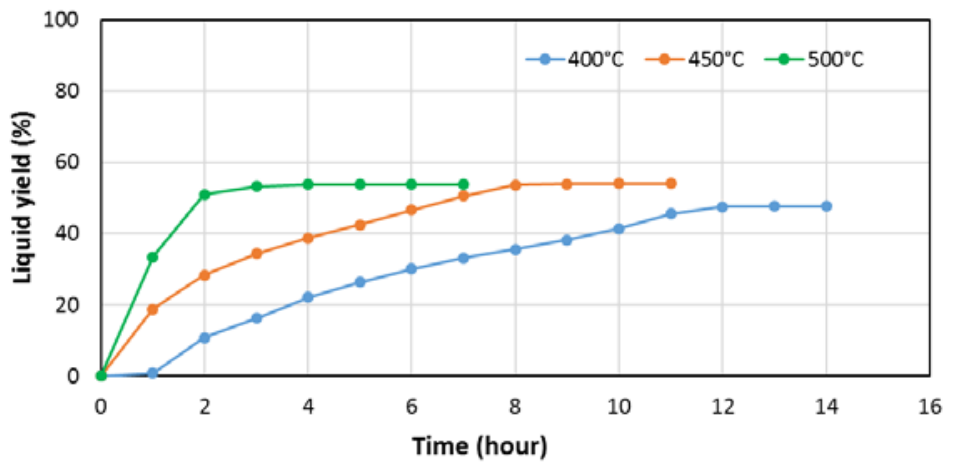

Figure 10. Liquid oil production rate at various temperature collected from condenser 1 for CCS feedstock

Pyrolysis of CCS over CNZ catalyst produced highest liquid product at the catalyst to plastic ratio of 0.25 which could obtain the liquid yield of $61.85 \%$. The oil yield just slightly lower than that of thermal pyrolysis. The reason is that the CNZ catalyst was insuficient to crack the CCS which has higher dissociation energy compared to CINP. As can be seen in the previous study [5], CNZ has lower BET surface area than that of commercial catalyst. Lower surface area would give less contact between catalyst and waste plastic which means more pyrolytic gas would be cracked to produce shorter chain hydrocarbons.

The liquid oil production rate obtained from the thermal pyrolysis of CCS at various temperatures generated from the first condenser can be seen in Figure 10. Like CINP pyrolysis, the liquid yield was also mainly produced from the first condenser. The second condenser had only obtained the oil less than $10 \%$.

Figure 10 also shows that the fastest pyrolysis process can be achieved within 7 hours at the temperature of $500^{\circ} \mathrm{C}$, while the longest time was 14 hours at the temperature of $400^{\circ} \mathrm{C}$. The pyrolysis time of CCS was longer than that of CINP. This is due to the higher dissociation energy of CCS compared to CINP as already mentioned previously. It means that the CCS needs more heating fuel which affects the total operasional cost of the plant.

Table 1. Heating value of CINP and CCS pyrolytic oil

\begin{tabular}{|c|c|c|}
\hline Material & $\begin{array}{c}\text { Temperature } \\
\left({ }^{\circ} \mathrm{C}\right)\end{array}$ & $\begin{array}{c}\mathrm{HHV} \\
(\mathrm{MJ} / \mathrm{kg})\end{array}$ \\
\hline \multirow{2}{*}{$\begin{array}{c}\text { Crushed instant } \\
\text { noodle packs (CINP) }\end{array}$} & $\begin{array}{c}450 \\
\text { (Condenser 1) }\end{array}$ & 36,99 \\
\cline { 2 - 3 } & $\begin{array}{c}450 \\
(\text { Condenser 2) }\end{array}$ & 36,45 \\
\hline $\begin{array}{c}\text { Crushed coffee } \\
\text { sachets (CCS) }\end{array}$ & $\begin{array}{c}500 \\
\text { (Condenser 1) }\end{array}$ & 35,43 \\
\hline
\end{tabular}

The heating value of the pyrolytic oil produced from the pyrolysis of CINP and CCS is shown in Table 1 . The result shows that the heating value was high enough for fueling the engine and other external combustion engines such as furnace, stirling engine, and cooking stove. However, the heating value was slightly lower than that of commercial fuel such as gasoline, kerosene, and diesel fuel which is normally more than $40 \mathrm{MJ} / \mathrm{kg}$. Some impurities in real waste plastic might be the the main reason for this result.

\subsection{Carbon Atom Number Distribution of Liquid Oil}

The quality of the liquid product can be seen from the carbon atom number distribution. It can be used to classify the liquid oil based on the application such as gasoline and diesel fuel. Figure 11 shows the carbon atom number distribution obtained from the pyrolysis of CINP. It classified the liquid oil into three fraction of oil i.e. C5-C12 (gasoline), C13-C20 (diesel fuel) and >C20 (heavy oil). The result shows that CINP pyrolytic oil contained mostly gasoline fraction which amounts to more than $90 \%$. The presence of catalyst increased the gasoline frcation which means that some longer hydrocarbons were cracked into light hydrocarbons.
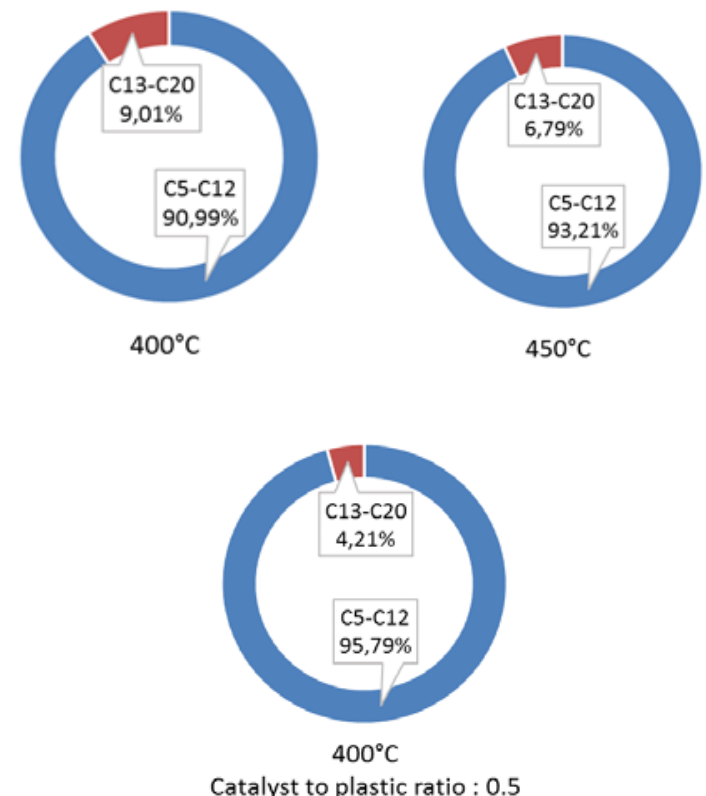

Figure 11. Carbon atom number distribution of liquid oil produced from the pyrolysis of CINP 
Figure 12 represents the carbon atom number distribution obtained from the pyrolysis of CCS. Th result shows that CCS pyrolytic oil contained heavy oil fraction at the temperature of $500^{\circ} \mathrm{C}$. The reason is that some CCS which could not be pyrolyzed at lower temperature would be pyrolyzed at higher temperature. As shown in Figure 8, CCS produced higher liquid fraction at higher temperature. It means that the increase of liquid fraction at higher temperature contributed to the presence of heavy oil in CCS pyrolytic oil. The presence of catalyst reduced the gasoline fraction at the catalyst to plastic ratio of 0.37 . The reason is that catalyst converted some gasoline fraction into gaseous product. This reason has been confirm from the data in Figure 9 where the liquid fraction was drastically decreased while the gaseous fraction increased.

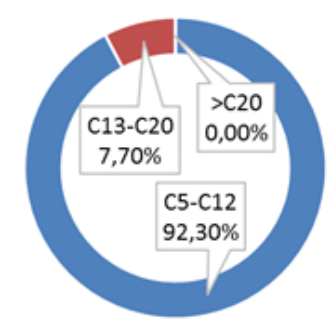

$400^{\circ} \mathrm{C}$

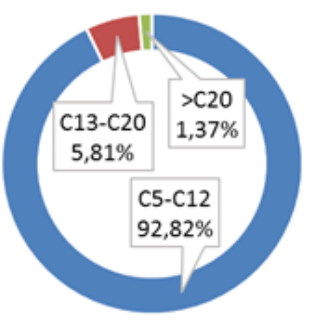

$500^{\circ} \mathrm{C}$

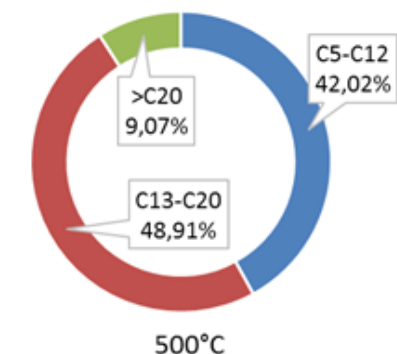

Catalyst to plastic ratio : 0.37

Figure 12. Carbon atom number distribution of liquid oil produced from the pyrolysis of CCS

\subsection{Char Residue}

Figure 13 shows the physical appearance of the char residue produced from the pyrolysis of CINP and CCS at the temperature of $450^{\circ} \mathrm{C}$. The result shows that CCS solid residue contained some aluminium foil which was laminated in coffee sachet. As shown in Figure 5 and 8, CCS feedstock produced more than $25 \%$ of solid residue while CINP feedstock produced less than $5 \%$ of solid residue. It means that about $20 \%$ of solid residue in CCS generated from aluminium foil. It can be recovered to produce aluminium bar for various application. The char residue can be used as co-firing fuel blended with coal or biomass for heating up the pyrolysis reactor or other applications.

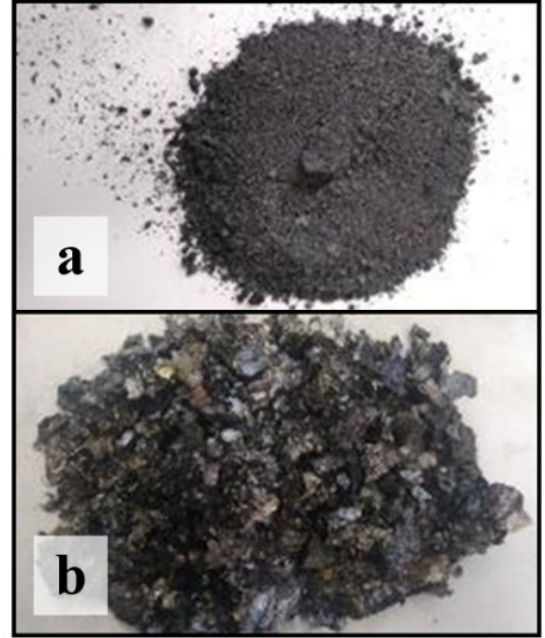

Figure 13. Char residue from the pyrolysis of (a) CINP and (b) CCS at the temperature of $450^{\circ} \mathrm{C}$

The utilization of char residue derived from the pyrolysis of waste plastic has been studied by Jamradloedluk and Lertsatitthanakorn [21] to boil the water in a cookstove. The char-derived briquette needed a longer time to ignite compared to wood fuel. Another study has also been investigated by Saptoadi et al. [22] to make hollow cylinder briquettes from various waste plastic char. Some char briquettes were not feasible since they melt during the combustion test.

A small portion of solid residue was found in catalyst. The snapshot of CNZ catalyst after use in pyrolysis of CINP and CCS can be seen in Figure 14. The colour appearance of both used catalysts seem darker than fresh CNZ catalyst. It means that some coke formation have appeared in used- catalysts. The presence of coke formation would deactivate the catalyst which would reduce the catalytic activity of CNZ and finally would affect to the quality of the liquid oil. Real waste plastic also contained some impurities which contributes to the deactivation of catalyst. The used-catalyst can also be recovered by burning it to remove some cokes inside the catalyst.

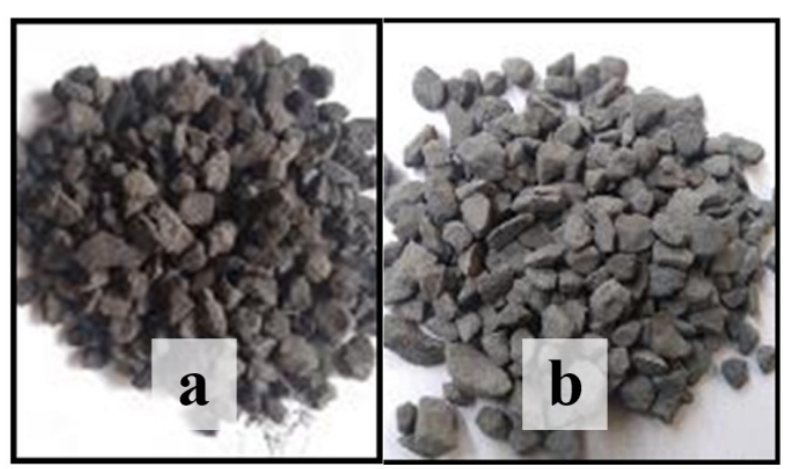

Figure 14. Used-catalyst after the pyrolysis of (a) CINP and (b) CCS 


\section{Conclusions}

The thermal and catalytic pyrolysis of CINP and CCS have been succesfully conducted in a vertical tubular reactor. The results show that CINP produced higher liquid product at lower temperature while CCS produced higher liquid product at higher temperature. The maximum liquid oil yield was up to $65 \%$ on CCS pyrolysis at the temperature of $500^{\circ} \mathrm{C}$. The presence of catalyst reduced the liquid fraction for both feedstocks and modified the chemical composition of the pyrolytic oil.

The heating value of the pyrolytic oil was high enough for fueling the engine and other external combustion engines such as furnace, stirling engine, and cooking stove. However, the heating value was slightly lower than that of commercial fuel such as gasoline, kerosene, and diesel fuel which is normally more than $40 \mathrm{MJ} / \mathrm{kg}$. CCS pyrolysis also produced much more solid product compared to CINP. The reason is that CCS was laminated by aluminium foil which could not be pyroyzed into pyrolysis gas. The aluminium foil remained in the reactor mixed with the solid residue.

\section{Acknowledgements}

This study is financially supported by the Ministry of Research, Technology and Higher Education, Republic of Indonesia through Fundamental Research Program [Grant No. 227/SP2H/LT/DRPM/2019]. The authors would also like to thank Gadjah Mada University for the product analysis.

\section{REFERENCES}

[1] Badan Pusat Statistik, Statistik Lingkungan Hidup Indonesia (SLHI) 2018, Jakarta, 2018.

[2] A. Jain, UNEP Summary Report: Waste Management in ASEAN Countries, Thailand, 2017.

[3] M. Syamsiro, D. Y. Mathias, H. Saptoadi, D. R. Sawitri, A.-S. Nizami, M. Rehan, Pyrolysis of Compact Disc (CD) Case Wastes to Produce Liquid Fuel as a Renewable Source of Electricity Generation, Energy Procedia. 145 (2018) 484-489.

[4] S. K. Tulashie, E. K. Boadu, S. Dapaah, Plastic waste to fuel via pyrolysis: A key way to solving the severe plastic waste problem in Ghana, Therm. Sci. Eng. Prog. 11 (2019) 417424. doi:10.1016/j.tsep.2019.05.002.

[5] M. Syamsiro, H. Saptoadi, T. Norsujianto, S. Cheng, Z. Alimuddin, K. Yoshikawa, Fuel oil production from municipal plastic wastes in sequential pyrolysis and catalytic reforming reactors, Energy Procedia. 47 (2014) 180-188.

[6] P. Das, P. Tiwari, The effect of slow pyrolysis on the conversion of packaging waste plastics (PE and PP) into fuel, Waste Manag. 79 (2018) 615-624. doi: 10.1016/j.wasman.2018.08.021.

[7] Y. Zhang, D. Duan, H. Lei, E. Villota, R. Ruan, Jet fuel production from waste plastics via catalytic pyrolysis with activated carbons, Appl. Energy. 251 (2019) 113337. doi:10.1016/j.apenergy.2019.113337.

[8] S.L. Wu, J.H. Kuo, M.Y. Wey, Thermal degradation of waste plastics in a two-stage pyrolysis-catalysis reactor over core-shell type catalyst, J. Anal. Appl. Pyrolysis. 142 (2019) 104641. doi:10.1016/j.jaap.2019.104641.

[9] S. Kumar, R.K. Singh, Optimization of process parameters by response surface methodology (RSM) for catalytic pyrolysis of waste high-density polyethylene to liquid fuel, J. Environ. Chem. Eng. 2 (2014) 115-122. doi:10.1016/j.je ce.2013.12.001.

[10] C. Muhammad, J.A. Onwudili, P.T. Williams, Catalytic pyrolysis of waste plastic from electrical and electronic equipment, J. Anal. Appl. Pyrolysis. 113 (2015) 332-339. doi:10.1016/j.jaap.2015.02.016.

[11] M. Syamsiro, S. Cheng, W. Hu, H. Saptoadi, N.N. Pratama, W. Trisunaryanti, K. Yoshikawa, Liquid and Gaseous Fuels from Waste Plastics by Sequential Pyrolysis and Catalytic Reforming Processes over Indonesian Natural Zeolite Catalysts, Waste Technol. 2 (2014) 44-51.

[12] M. Syamsiro, H. Saptoadi, M. Kismurtono, Z. Mufrodi, K. Yoshikawa, Utilization of waste polyethylene pyrolysis oil as partial substitute for diesel fuel in a DI diesel engine, Int. J. Smart Grid Clean Energy. 8 (2019) 38-47. doi:10.12720/sgce.8.1.38-47.

[13] H. Venkatesan, S. Sivamani, K. Bhutoria, H.H. Vora, Experimental study on combustion and performance characteristics in a DI CI engine fuelled with blends of waste plastic oil, Alexandria Eng. J. 57 (2018) 2257-2263. doi:10.1016/j.aej.2017.09.001.

[14] A.S. Ayodhya, V.T. Lamani, P. Bedar, G.N. Kumar, Effect of exhaust gas recirculation on a CRDI engine fueled with waste plastic oil blend, Fuel. 227 (2018) 394-400. doi:10.1016/j.fuel.2018.04.128.

[15] V. Chintala, P. Godkhe, S. Phadtare, M. Tadpatrikar, J.K. Pandey, S. Kumar, A comparative assessment of single cylinder diesel engine characteristics with plasto-oils derived from municipal mixed plastic waste, Energy Convers. Manag. 166 (2018) 579-589. doi:10.1016/j.enco nman.2018.04.068.

[16] D. Damodharan, B. Rajesh Kumar, K. Gopal, M.V.D. Poures, B. Sethuramasamyraja, Utilization of waste plastic oil in diesel engines: a review, Rev. Environ. Sci. Bio/Technology. 0123456789 (2019). doi:10.1007/s11157019-09516-X.

[17] I.C. Neves, G. Botelho, A. V. Machado, P. Rebelo, The effect of acidity behaviour of $\mathrm{Y}$ zeolites on the catalytic degradation of polyethylene, Eur. Polym. J. 42 (2006) 1541-1547. doi:10.1016/j.eurpolymj.2006.01.021.

[18] J. Aguado, D.P. Serrano, Feedstock Recycling of Plastic Wastes, the Royal Society of Chemistry, 1999. doi:10.103 9/9781847550804.

[19] N. Miskolczi, L. Bartha, G. Deák, B. Jóver, Thermal 
degradation of municipal plastic waste for production of fuel-like hydrocarbons, Polym. Degrad. Stab. 86 (2004) 357-366. doi:10.1016/j.polymdegradstab.2004.04.025.

[20] M.D. Wallis, S.K. Bhatia, Thermal degradation of high density polyethylene in a reactive extruder, Polym. Degrad. Stab. 92 (2007) 1721-1729. doi:10.1016/j.polymdegradsta b.2007.06.002.

[21] J. Jamradloedluk, C. Lertsatitthanakorn, Characterization and Utilization of Char Derived from Fast Pyrolysis of Plastic Wastes, Procedia Eng. 69 (2014) 1437-1442. doi:10.1016/j.proeng.2014.03.139.

[22] H. Saptoadi, T.A. Rohmat, Sutoyo, Combustion of char from plastic wastes pyrolysis, AIP Conf. Proc. 1737 (2016) 1-8. doi:10.1063/1.4949286. 